\title{
Childhood Obesity: A Major Public Health Challenge of 21st Century
}

\author{
Nighat Nisar
}

Global prevalence of childhood obesity is increasing and considered as the biggest public health challenge of the $21^{\text {st }}$ Century. It is rapidly affecting developing countries, specifically in urban cities. World Health Organization estimated that the number of overweight and obese children is over 41 million, If this number increases with the same pattern then this will rise up to 70 million by 2025, globally. ${ }^{1}$ In developing countries, rapid transition from underweight to overweight and obese children has also been noticed and needs attention to develop country-specific strategies to control this problem.2,3 Obese children are at greater risk of non-communicable diseases; notably cardiovascular diseases, diabetes mellitus, and hypertension. Rise in colorectal cancer and increased death rates from all causes have also been noticed. ${ }^{4}$ In several countries across the Globe, the prevalence of obesity was found to be $20 \%$ or more, which is an alarming situation. 5 A study conducted in various schools of Karachi, Pakistan, showed that $29.8 \%$ children were obese and overweight. The risk factors of obesity among school children were noted as sedentary lifestyles and increase duration of sleep when compared with normal-weight children. ${ }^{6}$ Childhood obesity is a growing concern in Pakistan, which needs attention of families, communities, organisations, and policy-makers.

This rapidly rising childhood obesity is a threat on health systems of countries in terms of increasing cost of health services and burden of non-communicable diseases. There are social and economic implications of childhood obesity, leading to limited economic growth because of burden on health systems. It is critical to target childhood by adopting strategy to promote a healthy lifestyle and in increase in life expectancy. Life-course studies suggest that interventions in early childhood have sustained effects on health, and influence on later lifestyle factors.

For meeting this challenge, a broad range of interventions are required at individual, family and community level, and evidence-based policy intervention at country level.

Department of Community Medicine, Dow Medical College, Dow University of Health Sciences, Karachi, Pakistan

Correspondence: Dr. Nighat Nisar, Department of Community Medicine, Dow Medical College, Dow University of Health

Sciences, Karachi, Pakistan

E-mail: nisarnighat@hotmail.com

Received: September 27, 2018; Accepted: October 06, 2018
Primary prevention starts from preconception, i.e. maternal health and nutrition during pregnancy as these have strong influence on childhood obesity. Interventions at birth, like breastfeeding promotion, weaning, complementary food and its composition have found beneficial effects to maintain healthy weight in childhood. It is also suggested to avoid excess amount of sugary beverages, snack high in fat, sugar, and salt in children's diet; and promote adequate physical activity to prevent obesity in first 1 - 2 years of life. Interventions applied at earliest stage of childhood will have great cumulative beneficial effect on later stages of life. The other interventions are: providing healthy environment and applying preventive strategies at individual eating behaviour, physical activity, peer group, family behaviours of food selection, lifestyle, dietary and physical activity pattern; which are helpful in protecting against excess weight gain and obesity. The preventions at individual and community level start from birth to adolescence, and are multifaceted which include: healthy weight, healthy physical, psychosocial, and cognitive growth and development. The major role in meeting childhood obesity challenge is to promote lifestyle modifications from early childhood, adopting behaviour to avoid obesity-related comorbidities, healthy protective eating habits and movement patterns, and awareness to create healthy body image among children. ${ }^{4}$

In developed countries, the policy initiatives for taxes and regulation of industries were taken to increase taxes on calorie-dense food and sugary alcoholic beverages to prevent obesity and overweight in children; but at the same time, reluctance was also noted in implementation.7,8 Similarly, in developing countries, junk food consumption and use of sugary caffeinated fizzy drinks were labelled as risk factors of obesity in children. Thus policies of taxes and regulation of industries were adopted with stronger emphasis as compared to developed countries to fight against obesity in children. ${ }^{9}$ The healthy food unaffordability in our country is a social and economic problem, so policies and programmes should be envisaged on making healthy foods availability such as whole grains, fresh fruits and vegetables at affordable price, and provision of healthy snacks and meals at school in cost-effective prices with ban on junk food availability in schools and surrounding environment. In our country, policy formulation is required for taxes and regulation on industries involved in high calorie energy-dense foods, 
high sugar containing beverages, and make healthy food availability in markets at affordable price.

\section{REFERENCES}

1. WHO. Commision on ending childhood obesity; 2016. http:// www.who.int/end-childhood-obesity/facts/en/

2. Muthuri SK, Francis CE, Wachira LJM. Evidence of an overweight/obesity transition among school-aged children and youth in Sub-Saharan Africa: A systematic review. PLoS One 2014; 9:e92846.

3. Rivera JÁ, de Cossío TG, Pedraza LS, Aburto TC, Sánchez TG, Martorell R. Childhood and adolescent overweight and obesity in Latin America: a systematic review. Lancet Diabetes Endocrinol 2014; 2:321-32.

4. WHO. Consideration of the evidence on childhood obesity for the commission on ending childhood obesity: Report of the Ad hoc working group on science and evidence for ending childhood obesity. Geneva: World Health Organization, 2016.

5. WHO. Childhood overweight obesity. 2010. http://www.who.int/ dietphysicalactivity/childhood/en

6. Mansoori N, Nisar N, Shahid N, Mubeen SM, Ahsan S. Prevalence of obesity and its risk factors among school children in Karachi, Pakistan. Trop Doct 2018; 48:1-4

7. Kraak VI, Vandevijvere S, Sacks G. Progress achieved in restricting the marketing of high-fat, sugary and salty food and beverage products to children. Bull World Health Organ 2016; 94:540-8.

8. Hawkes C, Harris JL. An analysis of the content of food industry pledges on marketing to children. Public Health Nutr 2011; 14:1403-14.

9. Popkin BM. Relationship between shifts in food system dynamics and acceleration of the global nutrition transition. Nutr Rev 2017; 75:73-82.

.......... 